\title{
SOBRE O CAPITAL SOCIAL EM ASSOCIAÇÕES COMUNITÁRIAS: uma análise socioantropológica
}

\author{
Paulo Sérgio Lima da Silva ${ }^{1}$
}

\section{Resumo:}

$\mathrm{O}$ artigo discute alguns dados oriundos de pesquisa de mestrado onde investigou-se como é garantida a vitalidade temporal de associações comunitárias localizadas em bairros periféricos da cidade de Belém (Pará). Foi utilizada a técnica etnográfica, com interações cotidianas, entrevistas, observações e levantamentos bibliográficos sobre a temática. As associações estudadas convivem com uma contínua escassez de recursos financeiros, materiais e humanos, e desenvolvem atividades nas áreas de assistência social e educação, voltadas para um público considerado em situação de vulnerabilidade social. As lideranças comunitárias e moradores locais foram interlocutores que se mostraram como agentes repletos de inventividades e estratégias no intuito de garantir recursos às associações das quais participavam. A análise amparada em Pierre Bourdieu (2000, 2007) e Robert Putnam (2006) permitiu desvelar e compreender facetas dessa dinâmica a partir da análise do capital social dos agentes locais.

Palavras-chave: associações comunitárias, capital social, vitalidade

\begin{abstract}
:
The article discusses some data from a master's research where it was investigated how the temporal vitality of community associations located in peripheral neighborhoods of Belém-Pa is guaranteed. The ethnographic technique was used, with daily interactions, interviews, observations and bibliographical surveys on the subject. The associations studied coexist with a continuous scarcity of financial, material and human resources, and they develop activities in the areas of social assistance and education for a public considered in situation of social vulnerability. The community leaders and local residents were interlocutors who showed themselves as agents full of inventions and strategies in order to guarantee resources to the associations in which they participated. The analysis supported by Bourdieu $(2000,2007)$ and Putnam (2006) allowed unveiling and understanding facets of this dynamic from the analysis of the social capital of local agents.
\end{abstract}

Keywords: community associations, social capital, vitality.

\footnotetext{
${ }^{1}$ Possui Mestrado em Sociologia e Antropologia pela Universidade Federal do Pará (UFPA). Graduação em Ciências Sociais, ênfase em Antropologia (UFPA). Atualmente é Antropólogo da Fundação Papa João XXIIIFUNPAPA, órgão de Assistência Social do município de Belém-PA. E-mail: paulo19mec@ yahoo.com.br.
} 


\section{Introdução}

Associação de moradores, centro comunitário, clube de mães ou, ainda, sociedade de amigos de bairro (SABs) são algumas denominações das associações comunitárias urbanas de bairro que se multiplicam pelas cidades brasileiras e congregam-se em entidades como a Confederação Nacional das Associações de Moradores (CONAM), fundada nos anos 1980. Esse conjunto expressivo de práticas associativas é composto por diferentes agentes, discursos, interesses, recursos, tamanhos e relações sociopolíticas.

Já na década de 1980, Zaluar (1985) relata o considerável crescimento e a importância política das associações de moradores no Brasil, afirmando também que a vizinhança, nas classes populares urbanas, surge enquanto foco de suas organizações políticas e culturais. É na mesma linha de raciocínio que Caldeira (1984 apud SILVEIRA, 2014) escreve que a atuação das Sociedades de Amigos de Bairro (SABs), em geral, se desenvolveu em duas direções: a promoção de atividades esportivo-recreativas e o encaminhamento ao poder público de reivindicações dos bairros pertinentes a serviços de infraestrutura urbana, normalmente, sob a forma de abaixo-assinados.

Nesse caminho, Gohn (2001) esclarece que, buscando construir uma sociedade mais igualitária, com menos injustiças sociais e acesso igualitário a direitos, vivemos a partir dos anos 1990 um novo ciclo de ação coletiva baseada não somente na contestação-pressão dos anos 1970, ou na pseudonegociação dos anos 1980, porém, sim “em práticas que envolvem um agir coletivo" (GOHN, 2001, p.84). Essa autora também destaca, no novo milênio, a retomada do movimento popular urbano de bairros e que a constituição de redes associativas por setores populares é fundada em uma cultura política de base local onde as formas de mobilização dependem de relações de sociabilidade. Esse conjunto de redes dá origem a verdadeiras comunidades políticas nas quais os atores sociais buscam concretizar seu direito a ter direitos (GOHN, 2001).

Assim, o interesse pela pesquisa que embasa este artigo parte da compreensão de organizações comunitárias como espaços encharcados de saberes e práticas abertas ao estudo das Ciências Sociais, dentre outras ciências. Essas associações comportam múltiplas dimensões, e interagem com inúmeras pessoas e outras organizações, mostrando-se, enfim, como espaços por onde circulam recursos diversos, permitindo que os sujeitos arquitetem estratégias para viver a cidade e seus direitos. Compreendo ainda que associações 
comunitárias podem contribuir, de diversos modos, na melhoria da qualidade de vida e bemestar dos moradores, bem como estimular atividades culturais, esportivas e educacionais.

O estudo desse conjunto de fenômenos é de extrema importância, pois tem potencial para colaborar com a compreensão dos processos presentes na atuação dessas entidades, desvelando dinâmicas de associativismo e participação social na periferia de uma cidade da região amazônica.

\section{O Centro Comunitário São Pedro e a Sociedade Comunitária São Francisco}

As associações pesquisadas são a Sociedade Comunitária São Francisco (denominada pelos integrantes apenas como "Sociedade") e o Centro Comunitário São Pedro (chamado pelos membros como "São Pedro"), localizadas em Belém/PA, nos bairros Alvorada e Campina de Itacará ${ }^{2}$, respectivamente. A escolha se deve ao fato de que são associações que executam diversos serviços comunitários e projetos sociais, quase todos por meio de convênios que, juntos, podem atingir somas anuais de mais de $\mathrm{R} \$ 100.000,00$. Soma-se a isso o fato de, por se localizarem em bairros vizinhos, estarem em um campo de ação semelhante, aspecto que permite um estudo comparativo, sendo que suas lideranças se conhecem e interagem em algumas situações específicas, como, por exemplo, em encontros promovidos pela Agência Distrital local, reuniões de conselhos municipais de políticas setoriais, e em capacitações promovidas pela prefeitura às entidades que executam serviços socioassistenciais por meio de convênio.

A Sociedade Comunitária São Francisco iniciou suas atividades por volta de maio de 1984; logo, já conta com 32 anos de atuação. Seu nome se deve a um dos membros fundadores, o qual exerceu a vice-presidência nos anos iniciais da associação e hoje já é falecido. Aliás, quase todas as pessoas que participaram do momento de fundação já faleceram. A única exceção é Dona ${ }^{3}$ Cristina, primeira presidente.

Consegui ter acesso à Ata de Fundação da associação cujo texto inicia relatando que:

Aos 10 [dez] dias do mês de maio do ano de 1984, na casa da senhora Cristina, um grupo de senhoras e senhores reuniram-se em Assembleia Geral, com a finalidade de fundar oficialmente a Sociedade Comunitária São Francisco, na oportunidade foi escolhida pelos presentes a senhora Cristina para presidir a reunião, assumindo a direção dos trabalhos precisamente às 16:30, que em breves palavras esclareceu a finalidade da reunião e os principais objetivos da Sociedade a ser fundada, a seguir

\footnotetext{
${ }^{2}$ Os nomes das associações comunitárias, bairros e de algumas pessoas mencionadas nesse artigo são fictícios, no intuito de preservar os interlocutores da pesquisa.

${ }^{3} \mathrm{O}$ pronome de tratamento Dona, ao longo do texto, também é referido apenas como $D$. .
} 
foi colocado em discussão o nome Sociedade Comunitária São Francisco, como ninguém questionou foi colocado em votação, sendo aprovado por unanimidade [...] (Ata de Fundação, 1984).

Nesse mesmo documento relata-se que, por sugestão de um dos associados, foi eleita a diretoria para o período de 1984 a 1986. Conforme descrito por D. Selma, atual presidente e filha da primeira líder da entidade, esse grupo de pessoas configurava-se como:

\begin{abstract}
Um grupo de ideias mesmo, de amigos. Porque a minha mãe veio morar pra cá e a minha mãe sempre foi ligada a essas coisas de movimento, é cearense, né? Chegou aqui era muito feio, era muito pobre, e tinha muita necessidade, então eu acho que foi mais assim uma ideia mesmo, de um grupo. Acho que partiu dela que tava aqui, e aí, não sei se isso é o verdadeiro, mas acho que partiu dela, e aí ela trouxe algumas pessoas pra agregar com ela e que viam também a necessidade" (D. Selma, 12/04/2016).
\end{abstract}

Ainda na Ata mencionada, é perceptivo o desejo entre os participantes de que aquela associação tivesse longa e frutífera vida. Dessa maneira, um dos associados "fez um apelo a todos os eleitos no sentido de envidarem todos os esforços para elevar a Sociedade recém fundada a um lugar de destaque", e a presidente também desejou aos empossados "votos de pleno êxito nas suas atribuições a fim de elevar bem alto o nome da Sociedade" (Ata de Fundação, 1984).

Interessante notar que, já nesse início, a entidade estabeleceu duas diretorias que ainda atualmente representam duas linhas de atuação consolidadas: a assistência social e a educação. Sobre tal fato a atual líder, dona Selma, descrevendo o momento de fundação, afirma que:

$\mathrm{Na}$ época, o que foi repassado pra gente foi que era uma necessidade de acolher as crianças, na educação infantil, eu acho que o primeiro olhar foi esse, a educação infantil. E aí foi feita uma reunião de amigos, não sei te dizer quantos, foi feita essa reunião, e aí definiram que ia sair um grupo pra montar a instituição (D. Selma, 12/04/2016).

Dona Selma informa também que inicialmente, juntamente com o projeto da educação infantil, foi montado um grupo de mães. Ainda segundo ela, já nesses anos iniciais havia a interlocução dos membros da "Sociedade" com políticos na busca da melhoria, ainda que mínima, da infraestrutura local. Ela expressa:

[...] aí, veio alguns políticos que fizeram a melhoria da comunidade. Eu me lembro que teve uma época que aquele Carlos Xerfan foi candidato, acho que aquele homem jogou mais de mil carradas de aterro dentro dessa baixada, porque aí em baixo era o lixão da [empresa] Phebo (D. Selma, 12/04/2016). 
Por sua vez, o Centro Comunitário São Pedro, segundo D. Deusa, uma das fundadoras, surgiu por volta de 1990 e teria sua fundação atrelada a um grupo de casais, moradores do bairro de Alvorada, que haviam se conhecido a partir da participação em um grupo de evangelização da Igreja Católica. Tratava-se do Encontro de Casais com Cristo (ECC), realizado na Paróquia de São Francisco, sendo um serviço da Igreja destinado às famílias. Segundo o Conselho Nacional do ECC, tal serviço tem o compromisso com a dignidade da pessoa humana e com a ideia de justiça social, almejando fazer com que os casais se integrem e desenvolvam atividades na comunidade e nas pastorais paroquiais, promovendo a convivência fraterna nas paróquias e fazendo com que os participantes estejam inseridos "na vida da paróquia" e assumam "a problemática da paróquia"4.

Dessa maneira, D. Deusa expõe que no contexto do ECC havia os diversos grupos, como os Grupos Amizade, Estrela, Aliança e o Perseverança, do qual ela fazia parte. Assim, seguindo a dinâmica do ECC, após os encontros na Paróquia de São João Francisco, os grupos eram destacados, de acordo com as áreas de moradia, e faziam reuniões nas casas de seus membros. D. Deusa descreve tais reuniões:

[...] então a gente reunia aqui na Estrada do Outeiro, na casa de um senhor, era lá que a gente se reunia [...] era muito bonito, a gente ia pra lá, conversava, lia a Palavra e tudo, e depois a gente fazia um lanche e vinha embora. Era muito bacana, a gente se ajudava um ao outro (D. Deusa, 17/10/2016).

Ainda segundo ela, o ECC “ajuda muito a gente ter certo conhecimento, e ter muitas amizades”. Foi no Grupo Perseverança que D. Deusa conheceu D. Cátia, uma personagem central para a fundação do Centro, sendo descrita como "muito católica", "muito esforçada" e "muito legal", e que juntamente com outros casais da comunidade deram vida à entidade. Nessa direção, foram motivados pelo desejo de ter um local fixo para realizarem seus encontros, como diz a referida fundadora: "pra receber as pessoas, pra gente fazer as nossas coisas que a gente gostava" e "pra gente não tá correndo pra um lado, pra outro". Assim como não dispunham do local preferencial, que seria a Capela de São Francisco, existente naquela localidade, pois o padre responsável por ela não permitia a sua utilização, eles decidiram comprar um terreno, contendo uma pequena casa de madeira. Ali puderam realizar seus trabalhos comunitários.

4 Informação disponível em: http://www.santuariodaesperanca.com.br/canal.php?codigo=14. Acesso: 20/12/2016. 
Atualmente, ambas associações ofertam, principalmente, serviços e projetos de educação e assistência social à população local. A principal fonte de recursos (financeiros, materiais e humanos) dessas entidades são convênios firmados com órgãos públicos da Prefeitura Municipal de Belém. Somam-se a esses recursos outros provenientes da contribuição financeira de moradores locais cujos filhos são atendidos na educação infantil, e doações eventuais do poder judiciário, políticos/candidatos e empresas privadas. $\mathrm{O}$ volume de recursos é sempre descrito pelas lideranças como insuficiente e variável, fazendo com que acumulem sucessos e insucessos em sua atuação ao longo dos anos.

\section{Sobre os bairros das duas associações e a comunidade local}

Como mencionado anteriormente, as duas organizações pesquisadas localizam-se em bairros periféricos de Belém/Pa. Esses são bairros contíguos e eminentemente residenciais com precários ou nenhuns serviços públicos urbanos. Para melhor caracterizá-los, e a população atendida pelas duas organizações, apresentam-se a seguir alguns dados sociodemográficos desses locais.

Quadro no 01- População residente, por sexo, nos bairros Campina de Itacará e Alvorada, Município de Belém- 2010.

\begin{tabular}{|c|c|c|c|}
\hline \multicolumn{1}{|c|}{ Bairro } & Mulheres & Homens & Total \\
\hline Alvorada & 10.136 & 9.576 & $\mathbf{1 9 . 7 1 2}$ \\
\hline Campina de Itacará & 13.840 & 12.882 & $\mathbf{2 6 . 7 2 2}$ \\
\hline Total & $\mathbf{2 3 . 9 7 6}$ & $\mathbf{2 2 . 4 5 8}$ & $\mathbf{4 6 . 4 3 4}$ \\
\hline
\end{tabular}

Fonte: IBGE, Censo 2010 / Anuário Estatístico de Belém, 2012.

Da análise do quadro, constata-se que o bairro Campina de Itacará possui o maior contingente populacional (26.722 habitantes), sendo ainda que nos dois bairros o quantitativo de mulheres é maior do que o de homens.

Quadro no 02- Domicílios particulares permanentes nos bairros Alvorada e Campina de Itacará, Município de Belém- 2010.

\section{\begin{tabular}{|l|l} 
Bairro & Domicílios
\end{tabular}}




\begin{tabular}{|c|c|}
\hline Alvorada & 5.164 \\
\hline Campina de Itacará & 7.054 \\
\hline Total & $\mathbf{1 2 . 2 1 8}$ \\
\hline
\end{tabular}

Fonte: IBGE, Censo 2010 / Anuário Estatístico de Belém, 2012.

Como era esperado, devido ao maior contingente populacional, o bairro Campina de Itacará registra uma quantidade de domicílios 26,8\% maior que o bairro Alvorada. Nesses bairros é importante mencionar a existência de aglomerados subnormais ${ }^{5}$.

Quadro no 03 - Pessoas de 10 anos ou mais de idade, por classe de rendimento nominal mensal, nos bairros Alvorada e Campina de Itacará, no Município de Belém - 2010.

\begin{tabular}{|l|c|c|c|c|c|c|c|c|c|}
\hline Bairro & Total & $\begin{array}{c}\text { Até 1/2 } \\
\text { salário } \\
\text { mínim } \\
\text { o }\end{array}$ & $\begin{array}{c}\text { Mais de } \\
\mathbf{1} \text { a 1 } \\
\text { salário } \\
\text { mínimo }\end{array}$ & $\begin{array}{c}\text { Mais de 1 } \\
\mathbf{a} \mathbf{2} \\
\text { salários } \\
\text { mínimos }\end{array}$ & $\begin{array}{c}\text { Mais de } \\
\mathbf{2} \text { a 5 } \\
\text { salários } \\
\text { mínimos }\end{array}$ & $\begin{array}{c}\text { Mais de } \\
\mathbf{5} \text { a 10 } \\
\text { salários } \\
\text { mínimos }\end{array}$ & $\begin{array}{c}\text { Mais de } \\
\mathbf{1 0} \text { a 20 } \\
\text { salários } \\
\text { mínimos }\end{array}$ & $\begin{array}{c}\text { Mais } \\
\text { de 20 } \\
\text { salári } \\
\text { os } \\
\text { mínim } \\
\text { os }\end{array}$ & $\begin{array}{c}\text { Sem } \\
\text { rendim } \\
\text { ento }\end{array}$ \\
\hline Alvorada & 16.448 & 1.078 & 3.994 & 2.550 & 1.322 & 299 & 47 & 8 & 7.150 \\
\hline $\begin{array}{l}\text { Campina } \\
\text { de } \\
\text { Itacará }\end{array}$ & 22.678 & 1.250 & 5.260 & 3.831 & 1.995 & 483 & 73 & 9 & 9.777 \\
\hline TOTAL & $\mathbf{3 9 . 1 2 6}$ & $\mathbf{2 . 3 2 8}$ & $\mathbf{9 . 2 5 4}$ & $\mathbf{6 . 3 8 1}$ & $\mathbf{3 . 3 1 7}$ & $\mathbf{7 8 2}$ & $\mathbf{1 2 0}$ & $\mathbf{1 7}$ & $\mathbf{1 6 . 9 2 7}$ \\
\hline
\end{tabular}

Fonte: IBGE, Censo Demográfico 2010/SEGEP, Anuário Estatístico de Belém, 2012.

Observando o Quadro n ${ }^{\circ}$ 03, constata-se que, entre os que possuem algum rendimento nos dois bairros, a maioria (9.254 pessoas) apresenta renda de mais de $1 / 2$ a 1 salários mínimos, logo, são classificados como indivíduos de baixa renda. Chama atenção ainda o total de 16.927 pessoas sem rendimento (43,3\% do total).

Debruçando-me rapidamente sobre o cotidiano dos dois bairros e um pouco de suas histórias de ocupação, é relevante mencionar que o Centro Comunitário São Pedro se localiza na Passagem Menino Jesus, um ramal da Rua Sete de Abril, sendo essa uma rua asfaltada, bastante ampla, com pequenos comércios, como padarias, bares, oficinas de bicicleta. A maioria das casas é de alvenaria. É uma rua onde à tarde e à noite os moradores sentam-se em

\footnotetext{
${ }^{5} \mathrm{O}$ conceito de aglomerados subnormais é aplicado pelo Instituto Brasileiro de Geografia e Estatística -IBGE, e faz referência a um conjunto constituído de, no mínimo, 51 unidades habitacionais (barracos, casas, etc.) carentes, em sua maioria, de serviços públicos essenciais, ocupando ou tendo ocupado, até período recente, terreno de propriedade alheia (pública ou particular) e estando dispostas, em geral, de forma desordenada e densa.
} 
frente de suas casas para "jogar conversa fora", observar os passantes e atualizar-se das novidades locais.

Vizinhos ao Centro Comunitário encontramos a Delegacia de Polícia, o Centro de Detenção Provisória, um quartel do Corpo de Bombeiros e a Escola Ivana dos Santos. Ao lado do Centro, temos a Capela da Granja. Por sinal, Seu José, um morador do bairro há 50 anos, conversou comigo, dando informações a respeito da empresa Granja e da formação do bairro. Morando lá desde que nasceu, quando lhe perguntei se sabia se aquela área foi fruto de ocupação, ele disse que havia sido uma "ocupação sadia", isto é, organizada, e que os terrenos haviam sido cedidos por altos funcionários da Granja para funcionários da empresa e algumas outras pessoas. Assim, seu pai, já falecido, que trabalhou por mais de 40 anos e se aposentou naquela empresa, ganhou o terreno localizado na Rua Sete de Abril, onde hoje mora com a mãe e irmãos. Entretanto, Seu José informa que não possuem o título de posse.

Segundo o morador, aquela área era formada por campina, ou seja, áreas de mato. Provavelmente o nome do bairro, Campina de Itacará, é originário deste fato. Ele afirmou também que chegou a trabalhar na Granja, que empregava cerca de 200 funcionários, e dava bastante lucro, mas na gestão do Governador Jader Barbalho, nos anos 1980, foi fechada sem motivo aparente.

A Sociedade Comunitária São Francisco, por sua vez, localiza-se na Passagem Campo Belo, outra ramificação a partir da Rua Sete de Abril ${ }^{6}$. Essa passagem começa estreita e asfaltada, com algumas lojas de venda de roupas, um salão de beleza e pontos de venda de lanches, com a maioria das casas de alvenaria, algumas com dois andares e outras em construção. Entretanto, aos poucos a passagem vai se alargando e prossegue com traçado irregular. Já próximo à associação há uma igreja Assembleia de Deus, sendo que a partir desse ponto a rua já não mais possui asfalto, mostrando-se de terra batida e se inicia um forte declive com variações no solo ocasionadas pela descida de água da chuva. A partir daí também fica mais notória a ausência de saneamento e a presença de espaços com mato alto, tornando-se latente o cenário de baixada recorrente na periferia belenense. Essa passagem,

\footnotetext{
${ }^{6}$ Conforme mencionei, as duas entidades têm sede em passagens (Passagem Menino Jesus e Passagem Campo Belo) da Rua "Sete de Abril", contudo, estão separadas por uma razoável distância, tendo a Feira da Sete de Abril entre elas. Essa feira (conhecida também como "Feira da Alvorada") apresenta-se como o principal local de aquisição de gêneros alimentícios, produtos e serviços diversos para os moradores locais, contando, por exemplo, com lojas de móveis, roupas, eletroeletrônicos, eletrodomésticos, materiais de construção, oficinas de bicicletas, acesso à internet, etc.
} 
com exceção de alguns momentos do dia, conta com considerável circulação de moradores e algumas crianças brincando na rua.

Um morador local, residente na referida passagem há 36 anos, afirma que quando sua família se mudou para lá "não tinha casa nenhuma, irmão. Só umas três casas eu acho que tinha aqui. Era só gapó, só mato, só água. Os moradores foram se multiplicando rápido". Ele complementa falando que "o pessoal fala que foi invasão, mas isso aqui não foi invasão não, isso aqui foi comprado".

\section{Lideranças em construção: a trajetória das atuais líderes das duas entidades.}

As linhas desse tópico almejam apresentar as atuais lideranças das organizações pesquisadas, entender sua formação política enquanto líderes e as compreensões subjetivas sobre porquê participar nas associações que presidem.

\section{"Tô totalmente envolvida nisso aqui, sentimentalmente e o corpo e alma":}

\section{apresentando D. Selma}

D. Selma reside na passagem onde se localiza a associação, tem 48 anos de idade, é casada e possui duas filhas. Em geral, expressa-se com uma voz acelerada, gesticula bastante e é bastante sorridente. Nasceu no Ceará, mas veio ainda criança, junto com sua família, para o Pará. Sua participação na "Sociedade" iniciou a partir do incentivo de sua mãe, D. Cristina, que foi uma das pessoas a participar do momento da fundação e em anos posteriores.

Dessa forma, D. Selma afirma que se envolveu nas atividades da entidade desde muito jovem. Sobre isso ela expressa, em tom de crítica, que sua mãe a "jogou nos compromissos" da associação. Contudo, ela também fala que rebate algumas críticas de seu marido quanto a sua participação dizendo que "ele não compreende, isso é espiritual (risos) eu acho que é até espiritual mesmo, sabia? Porque eu não consigo me desligar, me desagregar". Dessa forma, ao mesmo tempo que notamos em sua fala uma certa acusação por sua mãe tê-la direcionado ao serviço comunitário que, de certa forma, lhe impediu de prosseguir em seus estudos formais, D. Selma deixa transparecer em diversos momentos que gosta muito de sua atuação enquanto liderança comunitária. É assim que ela expressa:

[...] até hoje eu não tive prejuízo de ter trabalhado na comunidade voluntariamente muitas vezes, não tive prejuízo disso. Ao contrário, tudo que eu sou e o que eu tenho de conhecimento eu digo que foi por esse espaço que me deu. Porque de capacitação que eu já tive não tenho nem dedos pra contar, de conhecimento, de amigos que fiz. Também foi pela instituição que me levaram a conhecer uma, a conhecer outro e 
ter... acho que a Sociedade ela me deu essa bagagem de... não conhecimento no caso de conhecimentos de formação, mas no conhecimento de área, de trabalhos voluntários, de trabalhos dentro da comunidade. Tudo isso a gente fez; fez e faz (D. Selma, 12/04/2016).

Como disse, a atuação de D. Selma como líder comunitária tem muito a ver com a participação de sua mãe, descrita por ela como alguém que sempre agregava muitas pessoas ao seu redor. Relevante mencionar que D. Selma enxerga no fato de ela e sua família serem cearenses o motivo de sua atuação na vida comunitária, pois, segundo ela, os cearenses seriam mais inconformados e "esquentados" com coisas que não gostam, estando dispostos a mudar suas realidades por meio do movimento associativo. Dessa forma, em uma entrevista, ela expressou: “minha mãe sempre foi ligada a essas coisas de movimento, é cearense, né?”. Em outro momento da mesma entrevista e falando a respeito de ser cearense, ela afirma que:

[...] a gente não é muito conformado, a gente tem uma dinâmica assim... Eu tinha, eu nasci no Ceará e vim me embora muito pequena, oh meu Deus eu não acredito que a mamãe é desse jeito, porque a mamãe é esquentada demais. Um dia eu arrumei o bagulho de todos, eu disse assim mesmo 'nós vamos fazer uma viagem lá pro Ceará, vamos conhecer a família da mamãe'. Aí foi eu, as minhas filhas, a minha irmã, a minha sobrinha, a mamãe, fomos visitar os parentes. Mano do céu! Impressionante! Tem uma que é pastora, vive no meio da comunidade, tem um que vive no centro comunitário; eu digo 'meu Deus, só muda o lugar!' E as casas? Que são do mesmo jeito, lotada de gente. Eu digo 'misericórdia!' O jeito que a mamãe tratava assim as pessoas, agregando. Mano, tenho uma tia, essa que é pastora, ela tem mais de 20 pessoas dentro da casa dela, diz que é tudo filho. De filho mesmo eu só sei que ela teve dois [risos], aí ela 'não, são meus filhos', eu digo 'ah meu Deus! 'É igual lá em casa, a mamãe era desse jeito, depois que nós crescemos foi que a gente foi diminuindo mais esse tipo de coisa [...] (D. Selma, 12/04/2016).

Observa-se por sua fala que a aptidão para ser uma líder comunitária se aproximaria da ideia de vocação, algo inerente. Contudo, autoras como Pereira (2002), Rodrigues (2013) e Piccolo (2006) defendem que uma liderança é uma construção com inúmeras variáveis envolvidas, ligadas a trajetórias familiares, profissionais, subjetivas, rede de relações, dentre outras. Interessante também quando D. Selma relaciona sua vida familiar com seu papel na comunidade. Nesse sentido, ela afirma:

[...] eu vi muitas coisas acontecendo dentro dessas duas situações, entidade comunitária e a nossa casa. Eu não conseguia entender como eu vou ser uma liderança da rua se eu não sou liderança da minha casa. Eu sempre tive uma grande preocupação, pra ti ver que as minhas filhas, graças a Deus, o meu marido, graças a Deus também, são pessoas que me escutam, são pessoas que me escutam e que me respeitam e assim na comunidade. Eu nunca deixei, às vezes tem gente que diz 'ah, 
eu larguei a minha família', nunca larguei a minha família. Sempre eu tratei os dois. O momento da comunidade é da comunidade, o momento da minha casa é da minha casa. Antigamente era muito mais rústico e o pessoal batia de madrugada pra gente ajudar, levar pro hospital e tudo. Essas coisas foram trabalhadas porque a mamãe era assim, ela abria, sabe, as coisas, e quando veio pra minha mão eu já comecei a trabalhar [...] (D. Selma, 12/04/2016).

Em suas palavras reforça-se o quanto é relevante a ideia de "liderança", como uma construção que passa pelas diversas esferas da vida e que exige esforços contínuos no sentido de buscar um equilíbrio, nem sempre alcançado.

Quanto às duas filhas, uma delas é contadora, casada e tem uma filha, a outra, Carol, é formada em administração e mora com D. Selma. Atualmente, Carol é a presidente de direito da entidade (eleita por Assembleia e registrada em Ata) e exerce funções na organização de atividades, projetos e serviços socioassistenciais desenvolvidos na "Sociedade". Contudo, semelhante ao "São Pedro", a presidência de fato é exercida por outra pessoa: D. Selma. Daí que me refiro a ela como presidente durante todo texto. Interessante notar que as duas lógicas (presidente de fato e de direito) parecem conviver sem atritos entre os integrantes das duas associações, atendendo, assim, a necessidades internas e externas (obrigatoriedade de eleição quadrienal da diretoria de associações).

Salienta-se que D. Selma participa ativamente do Conselho Municipal dos Direitos das Crianças e Adolescentes (COMDAC), onde é uma das conselheiras. Essa participação é estratégica para a entidade, pois “é lá que a gente fica sabendo de muita coisa assim, 'ah, tem um recurso de tal coisa' [...]". Em sua fala, a presidente ressalta o saber em ação adquirido (CARDOSO, 2011), assim como as amizades e redes construídas ao longo de sua trajetória.

Ainda conforme D. Selma, a entidade seria uma das organizações futuramente beneficiadas com a implantação de um projeto no valor total de mais de $\mathrm{R} \$ 1.000 .000,00$, sendo este recurso oriundo de fontes como o Fundo Municipal dos Direitos da Criança e do Adolescente - FMCA, via COMDAC.

Tendo em vista a sua grande frequência ao COMDAC alguns membros da "Sociedade" chegam a brincar dizendo que vão perguntar à D. Selma se ela foi contratada por aquele Conselho. Por sinal, essa própria líder comenta, em tom de piada, que "se eu morrer, eu quero que cremem meu corpo e peguem as cinzas e joguem um pouco na frente da FUNPAPA [Fundação Papa João XXIII] e um pouco lá na frente do COMDAC”.

“Ela tem jogo de cintura, não deu aqui, ela vai ali": conhecendo D. Dolores 
D. Dolores residiu por um longo período próximo ao C.C. São Pedro. Contudo, no ano de 2016, ela se mudou para o bairro do Tucumã. Atualmente, tem 52 anos de idade, possuí estatura mediana, uma voz calma, fala com pouca gesticulação, mas com uma expressão facial carregada quando trata de assuntos da associação que the preocupam. Declara-se divorciada, formada em pedagogia, possui três filhos (dois homens e uma mulher), sendo um deles adotado. Destaca que sempre procurou ensinar seus filhos a realizar algumas atividades necessárias no dia-a-dia do Centro. Todavia, ela confessa que apenas dois deles gostam de ajudar, uma vez que o adotivo não gosta. Assim, ela chega à conclusão de que "tá no sangue".

O início do envolvimento de D. Dolores com o Centro Comunitário foi no ano de 2003, sendo que anteriormente ela participava "só de grupos católicos pela igreja mesmo, não participava assim de entidade".

Depois da saída de D. Tânia (ex-presidente do Centro), D. Dolores relata que teria recebido o convite de um amigo para compor uma chapa na eleição da entidade:

$\mathrm{Eu}$ recebi um convite em 2003. A comunidade tava formando uma chapa pra renovação da Diretoria do Centro Comunitário São Pedro que é de 4 em 4 anos e um dos membros dessa chapa ele teve que fazer uma viajem e aí teve que substituir alguém [...], me fizeram um convite e ai foi quando eu fui pega até de surpresa, mas eu aceitei o convite naquele momento (D. Dolores, 04/10/2016).

Assim, apesar de, segundo informações colhidas durante trabalho de campo, já estar à frente da entidade há aproximadamente dez anos, quando perguntada, D. Dolores refere apenas o período que esteve na presidência de direito do Centro, ou seja, quando seu nome consta como dirigente no estatuto da entidade; isto porque, ela sempre atuou como presidente de fato. Dessa forma, pude observar que D. Dolores, em obediência ao estatuto da entidade que prevê eleição de quatro em quatro anos, alterna o cargo de presidente, e atualmente a presidência de direito é exercida por D. Tereza de Souza, irmã de D. Dolores, com um mandato de 2014 a 2018.

Constato que no "São Pedro", muitas vezes, o início do envolvimento com a instituição se deu por meio do convite de "um amigo", então, conforme escreve Fontes (2003, p.160), vejo que "as redes sociais nas quais os indivíduos estão inseridos têm papel central na determinação de sua trajetória de participação [em movimentos associativos]".

Nesse sentido, D. Dolores é percebida como sinal de estabilidade e continuidade das ações do Centro. Sob sua administração a entidade cresceu, foram construídas mais salas de aulas, refeitórios, além de serem firmados convênios com órgãos públicos. Assim, por mais 
que determinadas pessoas dirijam críticas a alguns aspectos de sua gestão, muitos moradores falam que seu trabalho foi bastante positivo para o Centro. Ela assume então a imagem de uma liderança batalhadora, que "corre atrás", que tem "jogo de cintura".

A presidente sempre busca realçar os sacrifícios que faz em nome da entidade. Assim, ela chega a afirmar que é a única pessoa que não pode utilizar o espaço do Centro para fazer sua festa de aniversário, pois iriam falar que estaria gastando verba da entidade. No mesmo sentido, quando a entrevistei, ela me falou que "pode faltar um botijão de gás na minha casa, mas no São Pedro eu não deixo faltar".

Semelhantemente à presidente da Sociedade Comunitária São Francisco, D. Dolores descreve as dificuldades iniciais que enfrentou e algumas ainda experimentadas, queixando-se das inúmeras exigências da comunidade:

No início, foi muito difícil porque as pessoas se envolvem muito. A gente não tem mais uma privacidade, é tudo lá na casa do líder. É o líder que tem que resolver. Se precisa de um documento, se precisa de algum encaminhamento, uma orientação. Eles não sabem separar essa vida pessoal do líder com a família e lá na entidade. Eles não sabem separar, não respeita. Eles acham que pode bater a qualquer hora na casa do líder independente da hora, do dia, você tem que atender mesmo eles (D. Dolores, 04/10/2016).

Por sua dupla ou tripla jornada, as mulheres que atuam como lideranças comunitárias acabam por reorganizar sua "vida privada, vida social e vida política" (SOUZA-LOBO, 1991). Elas passam a ser cobradas tanto no universo familiar quanto no comunitário. É por isso que fazem questão de demonstrar que dão conta de ambas as esferas, deixando claro, contudo, o cansaço acumulado ao longo dos anos. Sobre isso, D. Dolores faz a leitura que os homens não dão conta de múltiplas funções tais como as mulheres, tão pouco têm paciência para lidar com a rotina de uma líder comunitária. Ela diz:

Sempre são as mulheres que estão em movimentos comunitários. Eu acredito, porque os homens são mais machistas, que têm que sustentar a casa e, como a mulher sempre arranja mais um tempo e ela faz mil coisas ao mesmo tempo, então ela não se sente cansada. Então se é ali, trabalhar fora, não sei, ela consegue conciliar. O homem, ele é muito assim, quieto. O homem ou ele trabalha, ele não consegue ser o dono da casa, cozinhar, lavar, cuidar das crianças e as mulheres não, elas são mais... elas têm mais isso. Eu acho que é isso que leva, isso é coisa de mulher, eles são muitos machistas, isso é coisa de mulher; e ficar esperando pra falar com políticos vai levar tanto tempo e aí os homens desistem muito rápido. As mulheres são muitos insistentes, eu acredito que é isso. São bem poucos... poucos homens [no movimento comunitário], muito pouco eles. [A Associação da] Terra Firme é um homem, Tapanã é um homem. É jogado sempre a mulher mesmo (D. Dolores, 04/10/2016). 
Souza-Lobo (1991) argumenta que a presença de homens ou mulheres nos movimentos é frequentemente analisada na perspectiva dos seus interesses, estando os homens vinculados por questões ligadas à produção e mulheres por temas ligados à reprodução. Contudo, a mesma autora defende que a separação produção/reprodução é facilmente contestada, pois as práticas produtivas e reprodutivas estão profundamente articuladas.

D. Dolores também expressa a aprendizagem acumulada e o prazer sentido por estar na direção do "São Pedro" por mais de dez anos:

Esse trabalho, que é um trabalho árduo, veio assim pra mudar a minha vida, ele transformou a minha vida. Tinha mais de 25 anos que eu tinha parado, tinha terminado o ensino médio, não tinha feito o superior, e comecei a trabalhar no centro comunitário e isso me incentivou. Eu precisava sim me capacitar, estudar mais, entender melhor e isso me levou a voltar a estudar, e hoje sou formada, sou pedagoga. Então isso pra mim foi uma vitória, eu venci como pessoa, apesar de não ter recursos financeiros, um retorno financeiro assim que a gente possa dizer, mas esse trabalho é muito gratificante pra mim, ele faz parte da minha vida. Eu acho que não consigo..., eu penso em terminar o restante da minha vida me doando pro outro (D. Dolores, 04/10/2016).

A construção e manutenção da liderança de D. Dolores se dá, assim, pelas ações que ela desenvolveu e desenvolve à frente da entidade, salientando ela que, no início de sua gestão, contou com a ajuda de um delegado de polícia atuante, na época, na Seccional de Polícia, próxima ao Centro. Foi esse delegado quem lhe instruiu sobre formas de obter parcerias para a entidade e, ainda, foi ele quem apresentou D. Dolores a uma promotora de justiça que viabilizou a inscrição do Centro na relação de entidades que podem receber auxílio dos penalizados em processos do Poder Judiciário local.

A rede de relações de D. Dolores mostra-se extremamente extensa. Assim, pude observar que ela conhece e mantém contato com muitas autoridades locais, como, por exemplo, oficiais da Polícia Militar, do Corpo de Bombeiros, conselheiros tutelares, bem como representantes de órgãos como o Centro de Referência em Assistência Social, Conselho Municipal dos Direitos das Crianças e Adolescentes (COMDAC), Conselho Municipal de Assistência Social (CMAS), Fundação Papa João XXIII (FUNPAPA), etc.

O fato de D. Dolores ter atuado no Conselho Tutelar é apontado por alguns funcionários do Centro como uma experiência que permitiu a ela estabelecer novos "contatos políticos". Quando entrevistei D. Dolores, ela não mencionou sua atuação no Conselho Tutelar, mas, de acordo com informações coletadas, ela trabalhou como suplente de uma 
conselheira tutelar no período de 2008 a 2011, tendo sido eleita para assumir como titular do cargo ainda no ano de 2011, porém, não chegou a tomar posse. Entretanto, por mais que D. Dolores atualmente não atue nesse órgão, ela mantém contato próximo com os atuais conselheiros. Pude comprovar isso em um dia no qual presenciei o fato de ela ter sido procurada por uma moradora local, interessada em obter um documento emitido pelo Conselho Tutelar e D. Dolores falou que poderia ligar para um amigo no Conselho.

A explicação sobre a motivação do engajamento na vida comunitária varia entre as duas lideranças. D. Selma atrela ao fato de ser cearense, D. Dolores afirma que é algo inerente. Ambas se construíram como mediadoras entre a população local e esferas governamentais, reduzindo distâncias e contribuindo na relação e comunicação entre diferentes agentes da vida social.

Assim, D. Selma foi diretamente influenciada por sua mãe e desde muito jovem passou a conviver com o universo do movimento comunitário. Kuschinir (1999) discute que a construção social de um mediador político mantém relação direta com sua trajetória de vida. Essa trajetória é o que Bourdieu (1996) chama de habitus. Não à toa D. Selma fala que "É mais forte que eu". Elas aprenderam a ser lideranças por meio de lições da vida cotidiana: insinuações, reprovações, silêncios, evitações, etc (BOURDIEU, 1996, p.151).

\section{Sobre o capital social nessas associações comunitárias}

Para dar conta do universo de demandas apresentados pelas comunidades, as lideranças locais lançam mão de variadas estratégias e táticas, entre elas, principalmente, as conexões com outras pessoas e instituições que possam permitir o acesso a alguma modalidade de recurso desejado. Essas conexões podem ser melhor compreendidas a partir do conceito de capital social nas perspectivas de Bourdieu (2000, 2007) e Putnam (2006). Nesse sentido, analisarei primeiramente o capital social das duas atuais lideranças comunitárias, mais à frente problematizarei o capital social das comunidades nas quais se localizam as associações.

Bourdieu (2007) compreende capital social ${ }^{7}$ como:

conjunto de recursos atuais ou potenciais que estão ligados à posse de uma rede durável de relações mais ou menos institucionalizadas de interconhecimento e de inter-reconhecimento ou, em outros termos, à vinculação a um grupo, como conjunto de agentes que não somente são dotados de propriedades comuns,

\footnotetext{
${ }^{7}$ Portes (2000) afirma que Pierre Bourdieu foi o responsável pela primeira análise sistemática contemporânea do capital social.
} 
(passíveis de serem percebidas pelo observador, pelos outros ou por eles mesmos), mas também são unidos por ligações permanentes e úteis (2007, p.67).

Observa-se, assim, que o capital social está diretamente relacionado às redes sociais e de sociabilidades ${ }^{8}$ nas quais um agente interage, variando conforme o quantitativo de pessoas que conhece e o grau de reconhecimento pelas mesmas. Bourdieu frisa também que o volume do capital social de um agente está diretamente vinculado à "extensão da rede de relações que ele pode efetivamente mobilizar e do volume do capital (econômico, cultural ou simbólico) que é posse exclusiva de cada um daqueles a quem está ligado" (2007, p.67). Ou seja, não basta a um agente ter muitas relações, é necessário que as pessoas com as quais se relaciona detenham capitais múltiplos e úteis, considerando-se ainda que os capitais dessas pessoas têm o poder de multiplicar o capital possuído por um agente em particular.

O autor argumenta que o capital social, enquanto rede de ligações, é o produto de estratégias individuais ou coletivas de investimento social consciente ou inconscientemente direcionadas para a constituição ou a reprodução de relações sociais diretamente utilizáveis a curto ou longo prazo, devendo esse conjunto de relações implicar a existência de obrigações duráveis entre os agentes que assegurem o acesso a benefícios materiais e simbólicos (BOURDIEU, 2000). Essas obrigações podem ter uma fonte subjetiva (reconhecimento, respeito, amizade) ou ser garantidas institucionalmente (direito). Nessa perspectiva, Bourdieu, enxerga o capital social como um capital de obrigações e relações sociais podendo ser convertido em capital econômico, cultural e simbólico, dentre outros (BOURDIEU, 2000, p. 135-136).

A reprodução do capital social, segundo Bourdieu, depende de um "trabalho de sociabilidade, série continua de trocas onde se afirma e se reafirma incessantemente o reconhecimento". Exercer a sociabilidade exige dos agentes competência/talento para se relacionarem, habitus e "um dispêndio de tempo e esforços" (2007, p.68).

Nesse caminho, foi possível constatar que, durante suas trajetórias, as lideranças das duas associações vêm acumulando um vasto capital social e têm plena ciência da importância de participar em várias redes. D. Selma deixa isso claro ao afirmar, por exemplo, que:

\footnotetext{
${ }^{8}$ Portes (2000) chega a assinalar que o capital social é uma das consequências positivas da sociabilidade, argumentando ainda que Bourdieu defendeu uma utilização instrumental do conceito de capital social, enfocando os benefícios obtidos pelos indivíduos "em virtude da participação em grupos e na construção deliberada de sociabilidades tendo em vista a criação" desse capital (PORTES, 2000, p. 135).
} 
amizades são importantíssimas na hora de decidir alguma coisa, porque se tu não tem um amigo que te indique, que te fale, que te oriente, não acontece nada, então é necessário, é primordial a liderança ser uma pessoa 'lincada' com todos os segmentos e com todas as pessoas (D. Selma, 12/04/2016).

A presidente do "São Pedro", D. Dolores, tem uma fala semelhante ao falar que as amizades são muito importantes, "de todas as pessoas, tudo vem a somar. Hoje, que a gente diga, até o traficante lá da comunidade quero ser amiga dele, que ele me reconheça e me respeite para eu poder atuar dentro da comunidade". Essa presidente também reforça a importância das amizades como fonte de informação sobre verbas disponíveis: "as pessoas que me conhecem vão me indicando, vão me falando 'olha, tem projetos, faz um projeto, tem o edital, vai abrir isso, vai abrir aquilo', por meio disso a gente vai”.

A assistente social da "Sociedade" também salienta o quanto é importante a relação mantida com outros agentes:

\begin{abstract}
Porque quando eu consigo um parceiro que possa me fornecer o lanche, eu já não gasto com o lanche, eu posso tá investindo em uma outra coisa. Quando eu consigo um voluntário pra tá dando uma palestra, eu já não vou pagar um profissional, já vou ter um voluntário aqui. E a gente consegue. Todas as vezes que tem alguma coisa diferenciada que a gente precise de um parceiro pra vir a gente consegue. É do CRAS, da [Programa Estratégia] Saúde da Família, e outros que a gente vai buscando, que conhece o serviço e sabe qual é a importância e se coloca à disposição pra tá contribuindo de alguma forma (Amanda, 24/05/2016).
\end{abstract}

Dessa forma, as duas lideranças interagem em redes compostas, entre outros, por moradores próximos, políticos locais (vereadores, deputados, prefeitos, candidatos), autoridades públicas (secretários municipais e estaduais), funcionários públicos, representantes do Corpo de Bombeiros, de conselhos de políticas setoriais (Conselho Municipal de Assistência Social de Belém- CMAS, Conselho Municipal dos Direitos da Criança e do Adolescente- COMDAC, Conselho Municipal de Educação de Belém- CME) e de unidades do sistema municipal de saúde (postos de saúde). Além destes, interagem, ainda, com conselheiros tutelares, coordenadores de Centro de Referência de Assistência SocialCRAS, empresas privadas que são eventuais doadoras, o Ministério Público do Trabalho, o Tribunal de Justiça do Estado e o Ministério Público Estadual. Esses três últimos também como eventuais doadores. D. Selma afirma:

A gente vai ter que estreitar nosso relacionamento com o Ministério Público. Eles precisam saber que a gente tem [serviços]. A gente ainda não fez isso. Eu fui em uma reunião deles, mas não foi suficiente para falar dos nossos serviços, e assinar 
um convênio para que a gente volte lá e falar onde nós estamos inseridos. Esse estreitamento com o Ministério Público precisa ser feito. Mas com os outros órgãos a gente já tem meio que uma amizade, assim um vínculo bem profundo (D. Selma, 12/04/2016).

Refletindo sobre o processo de acumulação desse capital, cabe pontuar que D. Selma além de constituir seu próprio capital social, também herdou parte do capital de sua mãe, D. Cristina, ex-presidente e uma das fundadoras da associação, descrita como uma pessoa que estava sempre "agregando" outras ao seu redor. Já D. Dolores não contou com uma herança e constituiu seu capital a partir de ações empreendidas por ela mesma.

Dessa feita, as lideranças estão continuamente mapeando o que as pessoas têm a oferecer, construindo, a partir daí "ligações permanentes e úteis" (BOURDIEU, 2007, p.67). Além de instituir relações, é necessário mantê-las ao longo do tempo. É importante analisar também as estratégias de transmissão do capital social de uma coletividade/associação a um único agente. Essa concentração de capital social permite que um ou poucos indivíduos possam representar um grupo, falar e atuar em nome desse, exercendo um poder superior ao que possui considerando seu capital social isoladamente (BOURDIEU, 2000, p. 154-155). Nos casos das associações aqui analisadas, podemos considerar que ao capital social próprio das lideranças soma-se o capital social atribuído pela comunidade/ usuários dos serviços. Essa atribuição se dá mediante o reconhecimento e delegação, explícitos ou não, de uma parcela da comunidade. Reforço que as presidentes não contam com o apoio unânime da população local, de modo que a delegação de capital não se dá de forma expressa, mas sim a partir do momento em que se veem e são vistas como lideranças comunitárias por parte dos moradores.

Bourdieu (2000) assinala ainda que a conversão de capitais para um único agente integrante de um grupo pode se justificar na medida em que "quanto mais grande seja um grupo e menos poderosos seus membros, mais necessário se faz a delegação e a representação para concentrar o capital social” (p.155). Dessa forma, conforme analisa Pereira (2002) sobre um centro comunitário no bairro do Guamá/Belém,

a organização comunitária tornou-se uma Instituição re-inventada visto que funciona como uma espécie de representação paralela do chamado poder instituído legal, pois qualquer tipo de pedido que possa ser feito pelo Centro Comunitário a órgãos públicos ou privados, tem sempre um valor (p.60).

Os usos que as lideranças fazem desse capital social acumulado são diversificados, sendo ele, entre outros capitais, que também permite que elas participem de distintos espaços 
enquanto representantes comunitárias, angariando bens para uso coletivo (projetos e convênios) e também pessoal (prestígio ${ }^{9}$, empregos para familiares, etc).

O estoque de capital social das presidentes também ajuda a compreender a manutenção de suas lideranças na medida em que as tornam "merecedoras de crédito" (BOURDIEU, 2000, p.149). Bourdieu esclarece que a lógica da representação produz fenômenos como o "culto à pessoa" ou a "identificação de partidos, sindicatos e movimentos sociais com seu líder” (p.156). Nessa direção, a permanência ${ }^{10}$ delas ao longo dos anos faz com que, para alguns moradores, elas sejam percebidas como a própria associação que representam. Fenômeno semelhante foi verificado em pesquisas como a de Pereira (2002) e Barreto (2001). A primeira autora descreve uma situação exemplar que presenciou em campo quando um morador, ao ver a presidente do centro comunitário local que passava pela rua, verbalizou: "lá vai o Centro Comunitário", tendo ouvido também frases como "fulano é o Centro" (PEREIRA, 2002, p.89).

Barreto (2001), por sua vez, ao investigar os processos de mediação política em uma associação de moradores, observou a permanência de presidentes de sete até onze anos ininterruptos no cargo, fazendo com que, segundo a autora, a associação fosse quase que sinônimo de seu presidente. Tal característica também foi observada por Alvito (2001) quando em sua pesquisa, dentre outros aspectos, abordou o universo das organizações comunitárias. O mencionado autor expressa que as associações tendem a ser confundidas com seus líderes/presidentes, pois "busca-se a origem das ações nas pessoas, e não nas instituições ou processos" (p.122).

Em tal perspectiva, cabe também avaliar o capital social dos moradores fazendo uso das reflexões de Putnam (2006). Em um clássico estudo, o referido autor examina o funcionamento da vida cívica em regiões italianas (do sul e do norte), debruçando-se sobre a relação estabelecida entre comunidades locais e o desenvolvimento e desempenho de instituições políticas democráticas (governos regionais). Dessa forma, o autor consegue apreender algumas das condições necessárias para dar origem a instituições fortes, responsáveis e eficazes. O uso da teoria de Putnam é aqui cabível na medida em que ele se

\footnotetext{
9 Alvito (2001) escreve que “a palavra 'presidente' nunca é pronunciada sem uma entonação especial” (p.123) oriunda do prestígio envolvido.

${ }^{10}$ Machado da Silva (2011, p.703) verificou a permanência de lideranças nos cargos de direção de associações de moradores e pontuou: "A ausência de renovação torna-se evidente se consideradas, entre outras formas, as eleições com chapa única, bastante comuns; a apresentação de chapas em que há apenas um mero rodízio de cargos, já que todos ou quase todos os candidatos exerciam mandatos no período anterior; os diversos casos em que o presidente é reeleito indefinidamente".
} 
preocupa com o desempenho institucional e o porquê de algumas instituições alcançarem êxito e eficácia, e outras, fracassarem. Nesse sentido, o problema estudado pelo autor se aproxima do nosso. A aplicação da teoria desse autor se justifica também na medida em que, segundo Portes (2000), ele é responsável pelo caráter coletivo observado no conceito de capital social, onde passa a ser uma ferramenta de análise aplicável não apenas nos estudos de agentes individuais, mas sim de comunidades, cidades ou mesmo países inteiros.

Putnam (2006) enxerga na força ou fraqueza da comunidade cívica e na existência de capital social variáveis que explicam o desempenho institucional. Comunidade cívica ou vida cívica é por ele caracterizada como aquela onde existem cidadãos atuantes e impregnados de espírito público, por relações políticas igualitárias, por uma estrutura social baseada na confiança e na solidariedade (PUTNAM, 2006). Por sua vez, capital social "diz respeito a características da organização social, como confiança, normas e sistemas, que contribuam para aumentar a eficiência da sociedade" (p.177). Esse capital aumenta com o uso e diminui com o desuso, estando baseado em regras de reciprocidade generalizada, sociabilidade e sistemas de participação cívica onde se verificam práticas de mútua assistência ${ }^{11}$. As cadeias de relações sociais são outra forma de capital social, sendo que elas permitem "transmitir e disseminar confiança: confio em você porque confio nela, e ela me garante que confia em você" (p. 178). Putnam (2006) frisa ainda que o capital social constitui, em geral, um bem público, diferentemente de outros capitais que, quase sempre, são bens privados.

Considerando que a confiança é um componente básico do capital social e promotora da cooperação, observo que as lideranças aprendem, dia após dia, a jogar esse jogo e, com isso, acumulam amizades e inimizades ao longo do tempo, tendo em vista que o poder que exercem tem a capacidade de aproximar e afastar pessoas. Por outro lado, essa teia de relações marcadas por confianças e desconfianças pode minar ou enfraquecer o capital social das comunidades onde se localizam as entidades, influenciando na vitalidade dessas últimas, na medida em que impede ou dificulta a existência de uma rede de compromissos recíprocos e mútua confiança.

Considere-se ainda que a confiança, enquanto componente do capital social, "não é uma confiança cega. A confiança implica uma previsão do comportamento de um ator independente" (PUTNAM, 2006, p.180), ou seja, pensando no nosso caso, não se trata de

\footnotetext{
${ }^{11}$ Putnam dá o exemplo das chamadas associações de crédito rotativo, isto é, grupos nos quais cada um de seus membros contribui regularmente com um valor monetário, sendo que, de cada vez, um desses membros recebe a soma total arrecadada.
} 
confiar irrestritamente nas palavras das lideranças. Para que haja confiança social, são imperativos a constituição e o exercício de regras de reciprocidade entre os membros de uma comunidade, bem como a efetivação de sistemas de participação cívica. Tal participação se mostra parcialmente restrita nas duas associações estudadas, tendo em conta a forma verticalizada como ela, geralmente, se dá. Isso ocorre porque as lideranças centralizam as decisões, havendo permanência delas nos cargos e rotatividade de outros membros das associações (funcionários, presidentes de direito).

Pontua-se também que muitos dos outros membros, a exemplo de diretores e conselheiros fiscais etc, estão presentes apenas "no papel”, na Ata, pois não participam efetivamente do cotidiano das entidades. Pelo que observei, isso gera em alguns moradores a ideia de que as lideranças são "donas" das associações. Outros moradores utilizam essa afirmação como forma de criticar as presidentes: “isso aí é da família dela”.

Em sua pesquisa Alvito (2001) encontra fenômeno semelhante e esclarece que: “muitas vezes, não se diz o nome das associações de moradores, e sim a associação do fulano, a associação do beltrano (presidente). E os presidentes, por sua vez, veem as associações como suas [...]” (p.122). Dessa forma, uma moradora próxima ao Centro Comunitário São Pedro, referindo-se à presidente dessa entidade, expressa que "parece que ela é a dona ou ela é a presidente, parece, de lá do Centro".

A ausência de moradores nos quadros de direção parece, ainda, fortalecer a circulação de boatos que atentam contra a reputação de honestidade e confiança das lideranças, pois, como escreve Putnam (2006, p. 183), “os sistemas de participação cívica permitem que as boas reputações sejam difundidas e consolidadas”.

Alguns moradores locais afirmaram-me não serem chamados para tomar as decisões centrais das associações. As lideranças asseveraram que muitos moradores só aparecem nas reuniões quando há algum ganho material envolvido. Esse cenário de desconfianças e acusações gera pouco capital social e impede uma cooperação mais ampla, sendo que os dois lados saem prejudicados. Por outro lado, esse cenário é multifacetado e há formas de participação cívica de moradores das comunidades, em especial daqueles, de alguma forma, vinculados aos serviços das entidades. Como assevera Fontes (1991, p.367): “as organizações populares constroem toda uma rede de solidariedade social, que se configura em fórmulas cooperativas para o estabelecimento de serviços e instalação de equipamentos urbanos não 
ofertados pelo setor público". Entre esses serviços o autor destaca as creches comunitárias e os cursos profissionalizantes.

Dessa forma, muitos moradores locais participam regularmente das reuniões para discutir o andamento e dificuldades dos serviços e projetos ofertados. Debatem sobre atividades a serem realizadas (cursos, festas, reformas), assim como a respeito de projetos com recursos já escassos e estratégias a tomar no intuito de garanti-los. Na Sociedade São Francisco, por exemplo, segundo Eliana, uma das orientadoras do Serviço de Convivência, um atleta local, que "têm habilidades com artes maciais", sempre "ensina técnicas de defesa, [...] o que ele pode fazer em termos de alongamento, aquecimento, correr, essas coisas, ele faz com as crianças. Ele é um parceiro da comunidade, um apoio”. Outro morador, dono de um campo de futebol, cede aquele espaço para a realização de atividades de lazer com as crianças e adolescentes da associação.

É necessário ponderar também que, em variadas situações, a participação dos moradores se dá de forma indireta, isto é, quando eles determinam a manutenção ou extinção de determinada atividade (projeto social, por exemplo) a partir de sua procura e assiduidade naquele serviço. Esse aspecto faz com que as lideranças estejam sempre atentas ao que agrada ou desagrada aos usuários das atividades das associações que presidem.

\section{Concluindo}

O capital social das lideranças comunitárias, D. Selma e D. Dolores, apresenta características distintas do capital social dos moradores locais, contudo, em ambos os casos é possível perceber o quanto a influência e atuação de associações comunitárias depende da amplitude das redes de relações pessoais nas quais seus integrantes estão envolvidos e dos recursos disponíveis em cada rede. Considera-se, ainda, a relevância de um consolidado sistema de participação cívica, o qual pode, a depender de sua intensidade, fortalecer ou minar o capital social. Assim, enquanto espaços políticos as associações comunitárias despertam práticas pautadas por sociabilidades, mas também críticas e intrigas. Não há homogeneidade na forma como as lideranças são vistas pelos moradores, os elogios convivem com acusações e queixas.

Dessa maneira, durante o trabalho de campo pude ouvir críticas veladas e outras bem diretas sobre a atuação das atuais lideranças. Dentre elas, as acusações mais recorrentes giravam em torno da participação de seus familiares nas entidades, assumindo cargos 
remunerados e atuando na diretoria e organização administrativa. Surgiram comentários de diferentes moradores, como: "A moça que trabalha aí [presidente], ela envolve mais a família dela. A comunidade não tem muito acesso [...] porque todos que trabalham na parte de ensino, secretaria, não sei mais que lá, tudo é família, é irmã, é prima. [...] é essa que é a crítica; porque foi criado um centro comunitário, podia ser sorteado, né? Uma parte da família e uma parte da comunidade, pra saber o que se faz lá dentro, o quê que acontece, porque a gente não sabe como é que funciona, devido a essa coisa, por ser só família"; "Ela é um pouco polêmica, ela não te aceita com as tuas ideias, só a dela que é boa”; “[...] porque, na verdade, essas pessoas aí só procuram a gente quando é esse negócio de política...”.

Outras críticas questionavam os interesses das presidentes frente às entidades: "ela vê mais a parte lucrativa". Surgiram também queixas relacionadas ao não recebimento de serviços/benefícios que foram intermediados pelas associações, a exemplo do Programa Cheque Moradia. Assim, um morador local expressou: “Aqui deram muito Cheque Moradia pra pessoa que não era nem digna de receber, pras pessoas que precisavam mesmo, não deram. Na verdade, sempre por trás existe uma panelinha”. Algumas vezes o tom de acusação ficou tão expressivo que um dos moradores com o qual conversava foi advertido por outro: "olha, cuidado com as coisas que tu tá falando aí...”.

Esse conjunto de acusações é bem semelhante àqueles encontrados por Fonseca (2004) e, como diz a autora, "é difícil saber qual a parte da verdade nesses boatos" (p.55). Uma interlocutora com a qual conversei resume: "as pessoas falam mesmo, não tem como escapar, as pessoas criticam, as pessoas falam mesmo". Outro morador afirmou: "é aquela coisa... eles não vão poder agradar a todos, Jesus que é Jesus não agradou a todos".

Lembrando de Evans-Pritchard (2005), no clássico "Bruxaria, oráculos e magia entre os Azande", é importante considerar que acusações e contra-acusações entre membros de um grupo social podem assumir a forma de um instrumento público, um sistema de controle e restrição das ações próprias e alheias. Assim, aquele conjunto de acusações e intrigas que mencionei acima também funciona como uma forma de controle social da atuação das lideranças, fazendo com que elas sempre estejam atentas às possíveis consequências de seus atos na condução das associações. É daí também que Fonseca (2004) sinaliza o quanto as fofocas podem condenar transgressores, construindo uma imagem pública desejada ou indesejada, conferindo ou retirando autoridade e prestígio. 
Na mesma direção, Bourdieu (2010) sustenta que o homem político é continuamente julgado por um "tribunal da opinião", que precisa vê-lo como alguém digno de confiança e honrado, estando, assim, "especialmente vulnerável às suspeitas, às calúnias, aos escândalos" (2010, p.188), exigindo-se dele prudência, silêncios e dissimulações, pois "o homem político retira sua força política da confiança que um grupo põe nele" (p.188).

Por fim, constata-se que o capital social das lideranças e moradores ajuda a entender como se garante a vitalidade temporal das associações, pois é por meio de táticas baseadas no aumento e uso desse capital que os agentes têm conseguido obter recursos financeiros, materiais e humanos, sem os quais atividades básicas de atendimento à população local não poderiam ser executadas.

\section{Referências bibliográficas}

ALVITO, Marcos. As cores de Acari: uma favela carioca. Rio de Janeiro: Editora FGV, 2001.

BARRETO, Alessandra. "O paraíso efêmero: trajetória e mediação no Leblon”. In: VELHO, Gilberto; KUSCHNIR, Karina (orgs.). Mediação, cultura e política. Rio de Janeiro: Aeroplano, 2001. p.165-184.

BARROS, Joana. Participação popular em Belém: a experiência do congresso da cidade e do orçamento participativo e a sociabilidade política brasileira. 2012. Tese (Doutorado), Programa de Pós-Graduação em Sociologia, Universidade de São Paulo/USP, São Paulo - SP.

BOURDIEU, Pierre. Razões práticas: Sobre a teoria da ação. Tradução: Mariza Correa Campinas, SP: Papirus. 1996.

Escritos de educação. Maria Nogueira e Afrânio Catani (orgs.). 9 ed. Petrópolis, RJ: Vozes, 2007.

"Las formas del capital". In: Poder, derecho y clases sociales. $2^{\text {a }}$ Ed. Desclée de Brouwer: Bilbao, 2000.p.131-164.

O poder simbólico. 13 ${ }^{\text {a }}$ Ed. Rio de Janeiro: Bertrand Brasil, 2010.

CALDEIRA, Teresa. Cidade de muros: crime, segregação e cidadania em São Pedro. São Paulo: Editora 34/Edusp, 2000.

CARDOSO, Ruth. Ruth Cardoso: obra reunida. Teresa Caldeira (org.). São Paulo: Mameluco, 2011.

EVANS-PRITCHARD, Edward. Bruxaria, oráculos e magia entre os Azande. Rio de Janeiro: Zahar, 2005. 
FONSECA, Claudia. Família, fofoca e honra: etnografia de relações de gênero e violência em grupos populares. 2.ed. Porto Alegre: Editora da UFRGS, 2004.

FONTES, Breno. "Sobre a sustentabilidade das associações voluntárias em uma comunidade de baixa renda". Tempo Social, São Paul:, vol.15 no. 1, 2003. Disponível em: < http://www.scielo.br/pdf/ts/v15n1/v15n1a09.pdf>. Acesso: 04 out. 2016.

"Poder local e organizações populares". In: REUNIÃO DE ANTROPÓLOGOS DO NORTE E NORDESTE, 1991, Recife. Anais. Recife: p.639-649.

GOHN, Maria. Educação não-formal e cultura política: impactos sobre o associativo do terceiro setor. São Paulo: Cortez, 2001.

KUSCHNIR, Karina. Eleições e representação no Rio de Janeiro. Rio de Janeiro: Relume Dumará: UFRJ, Núcleo de Antropologia da Política, 1999.

MACHADO DA SILVA, Luiz. "A política na favela". Dilemas: Revista de Estudos de Conflito e Controle Social - Vol. 4 - no4, p. 699-716- OUT/NOV/DEZ 2011. Disponível: <https://revistas.ufrj.br/index.php/dilemas/article/view/7275>. Acesso: 14 out. 2016.

PEREIRA, Tânia. Um centro comunitário entre o real e o ideal: um espaço de educação política? 2002. Dissertação (Mestrado em Antropologia), $\mathrm{CFCH}$, Universidade Federal do Pará, Belém - PA.

PICCOLO, Fernanda. Sociabilidade e conflito no morro e na rua: etnografia de um centro comunitário em Vila Isabel/RJ. 2006. Tese (Doutorado em Antropologia), Programa de PósGraduação em Antropologia Social/Museu Nacional, Universidade Federal do Rio de Janeiro/UFRJ, Rio de Janeiro - RJ.

PORTES, Alejandro. "Capital social: origens e aplicações na sociologia contemporânea". In: Sociologia, problemas e práticas, $\mathrm{n}^{\circ}$ 33, p. 133-158, 2000. Disponível em: $<$ http://www.scielo.mec.pt/scielo.php?script=sci_arttext\&pid=S087365292000000200007>. Acesso: 08 jan. 2017.

PUTNAM, Robert. Comunidade e democracia: a experiência da Itália moderna. Trad. Luiz Monjardim. 5 ed. Rio de Janeiro: Editora FGV, 2006.

RODRIGUES, Milleny. O bairro e a política: a associação de moradores e a construção de uma liderança. 2013. Dissertação (Mestrado em Desenvolvimento Regional), Universidade Federal do Amapá/UFAP, Macapá - AP.

SILVEIRA, Laís. Política e território: etnografia das práticas políticas dos membros de uma associação de moradores no Grajaú. 2014. Dissertação (Mestrado), Programa de PósGraduação em Antropologia Social, Universidade de São Paulo/USP, São Paulo - SP.

SOUZA-LOBO, Elisabeth. A classe operária tem dois sexos: trabalho, dominação e resistência. São Paulo: Editora Brasiliense, 1991. 
ZALUAR, Alba. A máquina e a revolta: as organizações populares e o significado da pobreza. São Paulo: Brasiliense, 1985.

Recebido em: Agosto de 2017 Aprovado em: Dezembro de 2017 